\title{
Free space optical communication system for indoor applications based on printed circuit board design
}

\author{
Alsharef Mohammad ${ }^{1}$, Mohammed S. Alzaidi ${ }^{1}$, Mahmoud M. A. Eid ${ }^{1}$, Vishal Sorathiya ${ }^{2}$, \\ Sunil Lavadiya ${ }^{2}$, Shobhit K. Patel ${ }^{3,4}$, Ahmed Nabih Zaki Rashed ${ }^{5}$ \\ ${ }^{1}$ Department of Electrical Engineering, College of Engineering, Taif University, Taif, Saudi Arabia, \\ ${ }^{2}$ Department of Information and Communication Technology, Marwadi University, Rajkot, India \\ ${ }^{3}$ Department of Electronics and Communication Engineering, Marwadi University, Rajkot, India \\ ${ }^{4}$ Department of Computer Engineering, Marwadi University, Rajkot, India \\ ${ }^{5}$ Department of Electronics and Electrical Communications Engineering, Faculty of Electronic Engineering, Menoufia University, \\ Al Minufiyah, Egypt
}

\begin{tabular}{lll} 
Article Info & ABSTRACT \\
\cline { 1 - 2 } Article history: & $\begin{array}{l}\text { This study clarified an overview of wired and wireless optical } \\
\text { communication system block diagram with practical applications. Free- } \\
\text { space optical (FSO) communication is a trending field that is rising so fast to } \\
\text { Received Aug 27, 2021 } \\
\text { Revised Dec 1, 2021 } \\
\text { Accepted Dec 9, 2021 }\end{array} \quad \begin{array}{l}\text { replace electromagnetic waves in a communication, so we have presented a } \\
\text { theoretical circuit as an example and modified it to fit and work in } \\
\text { communication purposes, simulation is used and then practical work is done } \\
\text { and printed circuit board (PCB) is designed. Light emitting diode (LED) } \\
\text { have been used as transmitter and Photo Transistor as a receiver and variable } \\
\text { Keywords: }\end{array}$ \\
$\begin{array}{l}\text { Lightance to change voltage sent to the LED that indicates the change in the } \\
\text { transmitted signal }\end{array}$ \\
Phototransistor
\end{tabular}

Printed circuit board

Variable resistance

This is an open access article under the CC BY-SA license.

\author{
Corresponding Author: \\ Ahmed Nabih Zaki Rashed \\ Department of Electronics and Electrical Communications Engineering \\ Faculty of Electronic Engineering Menoufia University \\ Al Minufiyah, Egypt \\ E-mail: ahmed_733@yahoo.com
}

\section{INTRODUCTION}

The bit error rate (BER) is optimized with four-wave mixing (FWM) optical wavelength division multiplexing systems. The main target of work is to achieve the highest quality of services by reducing the BER effects. They have outlined the different optical multiplexing schemes such as orthogonal frequency division, wavelength division multiplexing (WDM), and dense wavelength division multiplexing (DWDM) schemes [1]-[8]. The applications of FWM is presented in order to achieve a minimum BER. The link budget and receiver sensitivity design are studied for different optical fiber lengths and signal attenuation to show the maximum Q-factor value and corresponding minimum BER values. Mathematical analysis, computer, and simulation programs are performed to estimate the optimum fiber optic cable length that achieves max. Q-factor value and min. BER values in the presence of non return to zero code modulation formats [9]-[18].

They have presented a competing survey about the BER optimization in optical fiber communication systems [19]-[25]. The BER is estimated mathematically in the presence of nonlinear distortion interaction and amplified spontaneous emission effect [26]-[30]. Return to zero, non return to zero signal generators are coupled with optical modulators for 8-bit sequence of (10101100) at power variations values from $15 \mathrm{dBm}$ to $20 \mathrm{dBm}$ to test the min BER values. Different optimization methods are employed in optical WDM systems using 
optisystem simulation [31]-[36]. Different gain flatness techniques for Erbium-doped fiber amplifier are investigated to test the min BER. The optical fiber length and pump power are optimized to test a required minimum BER, upgrade the optimum gain flatness and reduce the noise figure [37]-[45].

\section{MODEL RESEARCH DESCRIPTION}

Figure 1 detects an optical communication system block diagram, which consists of a transmitter unit, filter unit, and receiver unit. Figure 2 outlines the schematic view of the theoretical circuit of the optical communication system. Transmitter unit, which is followed by the transmission medium in the air and receiver unit. When there is a sound in front of the speaker the sound movers the layer on the speaker and moves the coil cutting the magnetic field so it produces an electro motive force (EMF). The electrical output signal from the microphone enters the capacitor $\mathrm{C} 1$, so it is charged and then release the charge so the signal is amplified and the signal output through the line 6 to the emitted diode that converts the signal into optical signal and transfers it in air.

As shown from the Figure 2(a) the transmitter of the optical communication system. Figure 2(b) the receiver of the optical communication system. Main three blocks of transmitter side are shown in Figure 3. The first block is the microphone, which is connected by a capacitor with value $10 \mu \mathrm{F}$ and ohmic resistance with value $1 \mathrm{~K} \Omega$. The second block is the integrated circuit, which is an integrated circuit (IC 741) which consists of two input port $(2,3)$ and one output port. Port No. 2 connected to a resistor with value $1 \mathrm{~K} \Omega$. Port No. 3 connected to the capacitor and resistor connected by a microphone. The output port connected to the emitting diode. The third block is the emitting diode connected to two resistors. Main four blocks of the receiver side are shown in Figure 4.

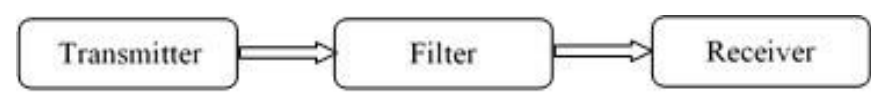

Figure 1. Optical communication system block diagram

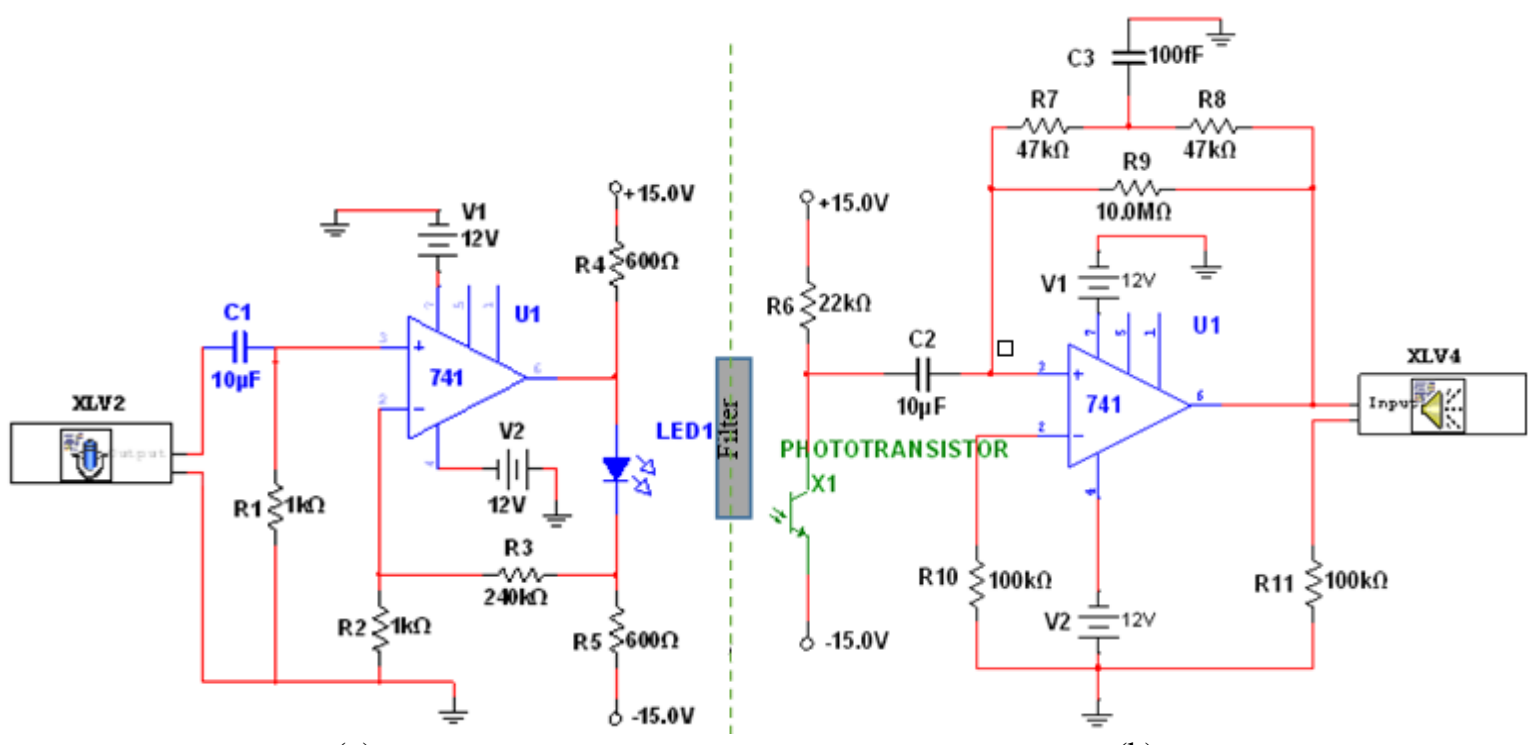

(a)

(b)

Figure 2. Schematic view of the theoretical circuit of the optical communication system, (a) Transmitter and (b) Receiver

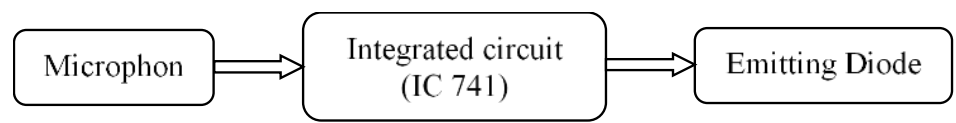

Figure 3. Transmitter unit block diagram 


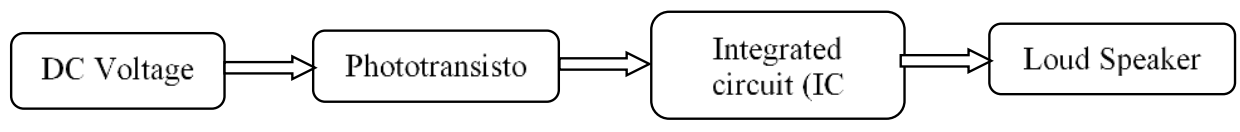

Figure 4. Receiver unit block diagram

The first block is the DC voltage, which contains DC source that supplies $+15 \mathrm{~V}$ DC and $-15 \mathrm{~V}$ DC. The second block is the transistor (TIL 78) connected to a resistor with value $22 \mathrm{~K} \Omega$ and capacitor with value $10 \mu \mathrm{F}$. The third block is the integrated circuit (IC 741), which consists of two input ports $(2,3)$ and one output port. Port No. 2 connected to the transistor. Port No. 3 connected to a resistor with value $100 \mathrm{~K} \Omega$. The output port connected to the loud speaker and other resistors. The fourth block is the loud speaker, which connected to a resistor with value $100 \Omega$. The light signal is received and enter the phototransistor TIL-78, which converts the light signal into an electrical signal and enter IC2 through the lines $2 \& 3$, which amplifies the signal through the line 6 then enter the speaker that converts the electrical signal to sound. Where Table 1 shows the types of all used resistors, capacitors, and miscellaneous with complete numerical values.

a) Resistance: Resistance plays important role in electronic components as it is the main role is to divide the voltage to make a difference in the voltage between two points. In addition, the resistance value can be fixed or variable depending on its nature. Resistance is independent of the voltage applied on it.

There are some cases at which nonlinear resistance is required; it is called voltage-dependent resistance (VDR). There is another type of nonlinear resistance, which is affected by the temperature, called thermistor. Moreover, the thermistor has two types negative temperature coefficient (NTC) and positive temperature coefficient (PTC). The third type of nonlinear resistance is the photoresistors, which value vary depending on the amount of light falling on it.

Table 1. Typical values for optical Tx./Rx. circuits

\begin{tabular}{ccc}
\hline Components & Definition & Values \\
\hline 1. Resistances & Carbon resistance & $1 \mathrm{k} \Omega$ \\
R1, R2 & Carbon resistance & $240 \mathrm{k} \Omega$ \\
R3 & Carbon resistance & $600 \Omega$ \\
R4, R5 & Carbon resistance & $22 \mathrm{k} \Omega$ \\
R6 & Carbon resistance & $47 \mathrm{k} \Omega$ \\
R7, R8 & Carbon resistance & $10 \mathrm{M} \Omega$ \\
R9 & Carbon resistance & $100 \mathrm{k} \Omega$ \\
R10 & Carbon resistance & $100 \mathrm{k} \Omega$ \\
R11 & \\
2. Capacitor & Chemical capacitor & $10 \mu \mathrm{f}$ \\
C1, C2 & Chemical capacitor & $100 \mu \mathrm{f}$ \\
C3 & Integration circuit & 741 \\
3. Miscellaneous & \\
IC1 & Integrion circuit & 471 \\
IC2 & Integration \\
IN & Bipolar diode & $\mathrm{TIL} 32$ \\
TR & Phototransistor & $\mathrm{TIL78}$ \\
MIC & Dynamic microphone \\
1.S & Speaker & $8 \mathrm{ohm}$ \\
\hline \multicolumn{3}{c}{} \\
\hline
\end{tabular}

b) Capacitors: Capacitors is one of the most important inactive components to store the electrical charges, also it blocks as current and filtering the signals. The simplest abstract for the capacitor consists of two plates in front of each other, each one is called a polar, and both are isolated and connected to one pair of the capacitor. One of the most common used capacitors is the chemical capacitor as it has high capacity value.

c) Integrated circuits: The integrated circuit is a full electronic circuit on a single chip of semiconductor usually silicon. In this circuit, we use the IC with number 741 which is used globally in different fields such as amplifying, annotation and comparing and it has a lot of advantages that have a high-value input resistance of $1 \mathrm{M} \Omega$, Has a low-value output resistance ranging in hundred of ohms, and has high voltage gain value around $10^{5}$.

d) Emitting diode: It is a diode consists of two semiconductors germanium and silicon has two ends, anode, and cathode. After the microphone converts the sound waves to electrical signals, the diode converts these signals into light-emitting signals; the diode TIL 32 is used. 
e) Phototransistor: It is an amplifying device consist of three main elements: emitter, base, collector. The phototransistor is used in the receiver circuit as it has the light as input and converts it into an electrical signal.

f) Microphone: A transducer converts the sound into an electrical signal; in the part of the transmitter of the circuit, a dynamic microphone is used.

g) Speaker: A device in the part of the receiver of the circuit, converts the electrical signal into sound and there are four types that are a namely electro-dynamic speaker, electromagnetic speaker, electrostatic speaker, and crystal speaker.

\section{RESULTS WITH DISCUSSIONS}

Communication system consists of a transmitter, medium, and receiver. The input signal, which is introduced through the microphone, is amplified. Light emitting diode (LED), which is placed on the output of the input circuit, emits light that represents the sound from the microphone. The emitted light is transmitted through the vacuum or optical fibbers to the phototransistor, that sense the changes on the received signals, the transistor amplifies the signal to move it to the speaker, that convert the signals into the sound which is heard by the recipient. The process is converting the voice to an electrical signal then light signal and vice versa on the receiver as shown in Figure 2. The transmitter circuit is a pulse width modulation (PWM) circuit connected to infrared (IR) LED when the potentiometer value is changed the on and off times of the LED is changed, means it changes the frequency of transmitted pulses, and the change in illumination of the LED is transmitted through the optical wireless medium as voltage pulses. The printed circuit board (PCB) design for transmitter circuit is clarified in Figure 5.

The receiver circuit uses phototransistor to gather the light pulses from the free space then transform it to an electrical signal. The receiver circuit and the PCB design for the receiver circuit is shown in Figure 6. This circuit can be used only in indoor applications as its range is very short $(1 \sim 2 \mathrm{~m})$ as the available power of transmitter LED is limited based on the clarified values in Table 2. But for using in long-distance the transmitter and power sources must be replaced by other stronger sources. The output of the circuit is measured using an oscilloscope to measure the frequency of the received pulses.

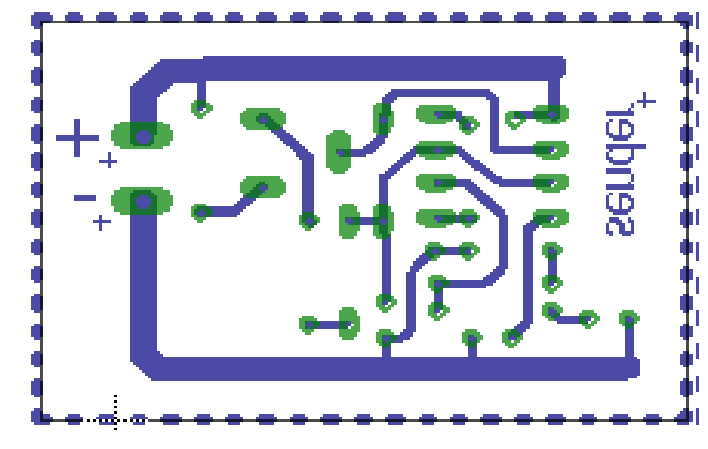

Figure 5. PCB design for the transmitter circuit

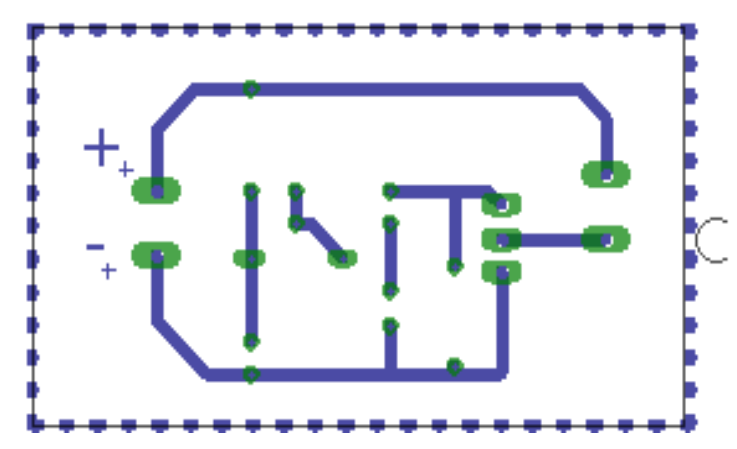

Figure 6. The PCB design for the receiver circuit

Table 2. The component used in both transmitter and receiver

\begin{tabular}{ccc}
\hline Component & Values & Amount \\
\hline Phototransistor & -- & 1 \\
LED IR & -- & 1 \\
Red LED & -- & 2 \\
Capacitor & $0.47 \mu \mathrm{F}$ & 1 \\
Capacitor & $0.1 \mu \mathrm{F}$ & 1 \\
Resistor & $100 \Omega$ & 2 \\
Resistor & $360 \Omega$ & 1 \\
Resistor & $10 \mathrm{~K} \Omega$ & 4 \\
Potentiometer & $50 \mathrm{~K} \Omega$ & 1 \\
Battery & $+9 \mathrm{~V}$ & 2 \\
\hline
\end{tabular}

Figure 7 shows the relation between voltage and time on the oscilloscope channel with time-division equal $0.5 \mathrm{~ms}$ and voltage division equal to $2 \mathrm{~V}$ while using the $1 \mathrm{~K} \Omega$ of the potentiometer. The illumination of the LED is low due to the low duty cycle of about $25 \%$. Second Case: using $10 \mathrm{~K} \Omega$ of the potentiometer. 
Figure 8 shows the relation between voltage and time on the oscilloscope channel with time-division equal $0.5 \mathrm{~ms}$ and voltage division equal to $2 \mathrm{~V}$ while using $10 \mathrm{~K} \Omega$ of the potentiometer. The illumination of the LED increased due to a higher duty cycle of $50 \%$. Third case: using $50 \mathrm{~K} \Omega$ of the potentiometer. Figure 9 shows the relation between voltage and time on the oscilloscope channel with time-division equal $0.5 \mathrm{~ms}$ and voltage division equal to $2 \mathrm{~V}$ while using $50 \mathrm{~K} \Omega$ of the potentiometer. The illumination of the LED increased due to a higher duty cycle with high frequency.

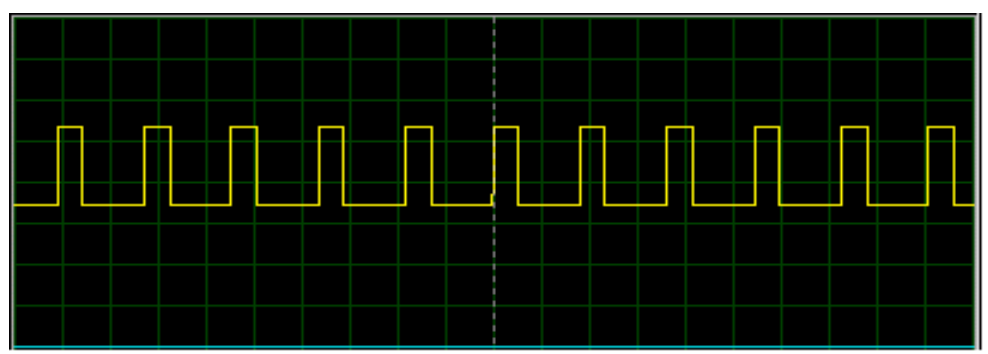

Figure 7. Voltage versus time at the receiver using $1 \mathrm{~K} \Omega$ of the potentiometer

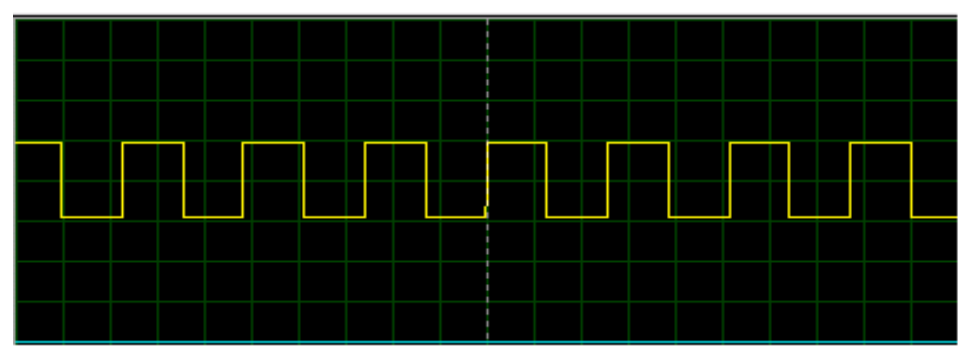

Figure 8 . Voltage versus time at the receiver using $10 \mathrm{~K} \Omega$ of the potentiometer

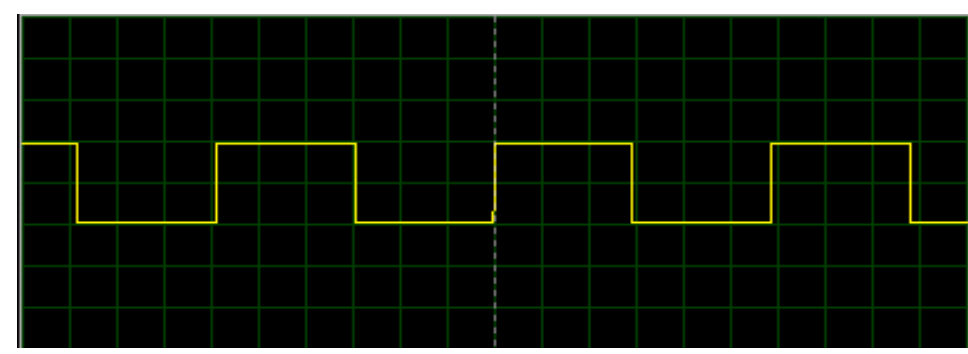

Figure 9. Voltage versus time at the receiver using $50 \mathrm{~K} \Omega$ of the potentiometer

\section{CONCLUSION}

In summary, free-space optical (FSO) is a trending field that is rising so fast to replace electromagnetic waves in communication. A theoretical circuit as an example and modified it to fit and work in communication purposes are presented. Simulation is used and then practical work is done, where printed board circuit is designed, using LED as transmitter and phototransistor as a receiver, also using variable resistance to change voltage sent to the light-emitting diode that indicates the change in transmitted signal.

\section{REFERENCES}

[1] J. Park, E. Lee, and G. Yoon, "Average bit-error rate of the Alamouti scheme in gamma-gamma fading channels," IEEE Photon. Tech. Lett., vol. 23, no. 4, pp. 269-271, February 2011, doi: 10.1109/LPT.2010.2100815.

[2] M. S. Mani Rajan and A. Mahalingam, "Nonautonomous solitons in modified inhomogeneous Hirota equation: soliton control and soliton interaction," Nonlinear Dyn., vol. 79, pp. 2469-2484, 2015, doi: 10.1007/s11071-014-1826-y.

[3] M. S. Mani Rajan and A. Mahalingam, "Multi-soliton propagation in a generalized inhomogeneous nonlinear Schrödinger Maxwell-Bloch system with loss/gain driven by an external potential," J. Math. Phys., vol. 54, pp. 04351-043527, 2013, doi: $10.1063 / 1.4798477$. 
[4] S. Das and E. Zahir, "Modeling and Performance Analysis of RoF System for Home Area Network with Different Line Coding Schemes Using Optisystem," International Journal of Multidisciplinary Sciences And Engineering, vol. 5, no. 6, pp. 1-8, June 2014.

[5] S. S. Kumar and P. Keerthana, "Simulation of RoF Using Wavelength Selective OADM," International Journal of Research Studies in Science, Engineering and Technology, vol. 2, no. 9, pp. 16-22, Sep. 2015.

[6] N. Singh and H. Kaur, "Amplitude Noise Reduction in Millimeter Wave Radio-Over-Fiber Systems by using Filtration Techniques," International Journal of Advanced Research in Computer and Communication Engineering, vol. 5, no. 7, pp. 302306, July 2016.

[7] K. Shrimali and A. Patel, "Performance Analysis of ROF System Using NRZ Coding," International Research Journal of Engineering and Technology (IRJET), vol. 4, no. 1, pp. 1568-1570, Jan. 2017.

[8] Y. Kim, S. Hur, H. Jang, and J. Jeong, "Theoretical and Experimental Study of Large Signal Chirp in Electro-Absorption Modulators Integrated DFB Lasers," Journal of the Korean Physical Society, vol. 37, no. 6, pp. 828-832, Dec. 2000, doi: $10.3938 / \mathrm{jkps} .37 .828$

[9] B. Stegmueller, E. Baur, and M. Kicherer, "15 GHz modulation performance of integrated DFB laser diode EA modulator with identical multiple quantum well-double stack active layer," IEEE Photon. Technol. Lett., vol. 14, no. 12, pp. 1647-1649, 2002, doi: 10.1109/LPT.2002.804664.

[10] D. A. J. Al-Khaffaf and I. A. Alshimaysawe, "Miniaturised tri-band microstrip patch antenna design for radio and millimetre waves of 5G devices," Indonesian Journal of Electrical Engineering and Computer Science, vol. 21, no. 3, March 2021, pp. 1594-1601, doi: 10.11591/ijeecs.v21.i3.pp1594-1601.

[11] D. A. J. Al-Khaffaf and A. M. Alsahlany, "A cloud VLC access point design for 5G and beyond," Optical and Quantum Electronics, vol. 53, pp. 472-481, August 2021, doi: 10.1007/s11082-021-03132-2.

[12] A. N. Z. Rashed, "Optical Wireless Communication Systems Operation Performance Efficiency Evaluation in the Presence of Different Fog Density Levels and Noise Impact," Wireless Personal Communications Journal, vol. 81, no. 1, pp. 427-444, March 2015, doi: 10.1007/s11277-014-2137-9.

[13] D. A. J. Al-Khaffaf and H. S. R. Hujijo, "High data rate optical wireless communication system using millimeter wave and optical phase modulation," ARPN Journal of Engineering and Applied Sciences, vol. 13, no. 23, pp. 9086-9092, Dec. 2018.

[14] V. W. S. Chan, "Free-space optical communications," J. Lightwave Tech., vol. 24, no. 12, pp. 4750-4762, 2006, doi: 10.1109/JLT.2006.885252

[15] R. N. Mahalati and J. M. Kahn, "Effect of fog on free-space optical links employing imaging receivers," Opt. Exp., vol. 20, no. 2, pp. 1649-661, 2012, doi: 10.1364/OE.20.001649.

[16] M. Rouissat, A. R. Borsali, and M. E. Chikh-Bled, "Free space optical channel characterization and modeling with focus on Algeria weather conditions," Int. J. Comp. Netw. and Infor. Secur., vol. 3, pp. 17-23, 2012, doi: 10.5815/ijcnis.2012.03.03

[17] A. Z. Suriza, I. M. Rafiqul, A. K. Wajdi, and A. W. Naji, "Proposed parameters of specific rain attenuation prediction for free space optics link operating in tropical region," J. of Atmosp. and Solar-Terres. Phys., vol. 94, pp. 93-99, 2013, doi: 10.1016/j.jastp.2012.11.008.

[18] A. Vavoulas, H. G. Sandalidis, and D. Varoutas, "Weather effects on FSO network connectivity," J. Opt. Comm. and Net., vol. 4, no. 10, pp. 734-740, 2012, doi: 10.1364/JOCN.4.000734.

[19] R. K. Crane and P. C. Robinson, "ACTS propagation experiment: rain-rate distribution observations and prediction model comparisons," Proc. IEEE, vol. 86, no. 6, pp. 946-958, 1997, doi: 10.1109/5.598417.

[20] R. E. Hufnagel and N. R. Stanley, "Modulation transfer function associated with image transmission through turbulence media," J. Opt. Soc. Am., vol. 54, no. 52, pp. 52-62, 1964, doi: 10.1364/JOSA.54.000052.

[21] R. K. Tyson, "Adaptive optics and ground-to-space laser communication," Appl. Opt., vol. 35, no. 19, pp. 3640-3646, 1996, doi: 10.1364/AO.35.003640.

[22] H. G. Sandalidis, "Performance analysis of a laser ground-station-to-satellite link with modulated gamma-distributed irradiance fluctuations," J. Opt. Comm. and Net., vol. 2, no. 11, pp. 938-943, November 2010, doi: 10.1364/JOCN.2.000938.

[23] M. G. Prabha and D. H. Margaret, "Analysis of Soliton Interaction with Higher Order Effects in Erbium-Doped Fiber," Asian Journal of Applied Science and Technology (AJAST), vol. 2, no. 2, pp. 591-598, April-June 2018.

[24] X. Liu, "Free-space optics optimization models for building sway and atmospheric interference using variable wavelength," IEEE Trans. Comm., vol. 57, no. 2, pp. 492-498, 2009, doi: 10.1109/TCOMM.2009.02.070089.

[25] A. Katsuyoshi, "Overview of the optical inter-orbit communications engineering test satellite (OICETS) project," J. Nat. Inst. of Info. And Comm. Tech., vol. 59, pp. 5-12, 2012.

[26] F. R. Gfeller and U. H. Bapst, "Wireless in-house data communication via diffuse infrared radiation," Proc. IEEE, vol. 67, no. 11, pp. 1474-1486, 1979, doi: 10.1109/PROC.1979.11508.

[27] A. M. Street, P. N. Stavrinou, D. C. O'brien, and D. J. Edwards, "Indoor optical wireless systems- A review," Opt. and Quant. Electr., vol. 29, pp. 349-378, 1997, doi: 10.1023/A:1018530828084.

[28] J. B. Carruthers and J. M. Kahn, "Angle diversity for nondirected wireless infrared communication," IEEE Trans. Comm., vol. 48, no. 6, pp. 960-969, 2000, doi: 10.1109/26.848557.

[29] R. Ramirez-Iniguez and R. J. Green, "Indoor optical wireless communications," in IEE Colloquium on Opt. Wireless Comm., vol. 128, pp. 14/1-14/7, 1999, doi: 10.1049/ic:19990705

[30] D. J. T. Heatley, D. R. Wisely, I. Neild, and P. Cochrane, “Optical Wireless: The story so far,” IEEE Comm. Mag., vol. 36, no. 12, pp. 72-74, Dec. 1998, doi: 10.1109/35.735881.

[31] H. T. Yura and W. G. McKinley, "Optical scintillation statistics for IR ground-to-space laser communication systems," Appl. Opt., vol. 22, no. 21, pp. 3353-3358, Nov. 1983, doi: 10.1364/AO.22.003353.

[32] M. Singh and J. Malhotra, "A high-speed long-haul wavelength division multiplexing-based inter-satellite optical wireless communication link using spectral-efficient 2-D orthogonal modulation scheme," International Journal of Communication Systems, vol. 33, Article No: e4293, 2020, doi: 10.1002/dac.4293.

[33] M. Singh, V. Dhasarathan, and J. Malhotra, "Development of high-speed FSO transmission link for the implementation of 5G and Internet of Things," Wireless Networks, vol. 26, pp. 2403-2412, 2019, doi: 10.1007/s11276-019-02166-5.

[34] M. Singh and J. Malhotra, "Performance Comparison of Different Modulation Schemes in High-Speed MDM Based Radio over FSO Transmission Link Under the Effect of Atmospheric Turbulence Using Aperture Averaging," Wireless Personal Communications, vol. 111, pp. 825-842, 2020, doi: 10.1007/s11277-019-06886-X.

[35] M. Singh and J. Malhotra, "Modeling and Performance Analysis of 400 Gbps CO-OFDM Based Inter-satellite Optical Wireless Communication (IsOWC) System Incorporating Polarization Division Multiplexing with Enhanced Detection," Wireless Personal Communications, vol. 111, pp. 495-511, 2020, doi: 10.1007/s11277-019-06870-5. 
[36] M. Singh and J. Malhotra, "Performance investigation of high-speed FSO transmission system under the influence of different atmospheric conditions incorporating 3-D orthogonal modulation scheme," Optical and Quantum Electronics, vol. 51, Article No: 285, 2019, doi: 10.1007/s11082-019-1998-2.

[37] M. Singh and J. Malhotra, “ $4 \times 20$ Gbit/s-40 GHz OFDM based Radio over FSO transmission link incorporating hybrid wavelength division multiplexing-mode division multiplexing of LG and HG modes with enhanced detection," Optoelectronics and Advanced Materials-Rapid Communications, vol. 14, no. 5-6, pp. 233-243, 2020.

[38] A. N. Z. Rashed, "High efficiency wireless optical links in high transmission speed wireless optical communication networks," International Journal of Communication Systems, vol. 27, no. 11, pp. 3416-3427, Nov. 2014.

[39] V. Sharma and N. Kumar, "Improved analysis of 2.5 Gbps-inter-satellite link (ISL) in inter-satellite optical wireless communication (ISOWC) system," Opt. Comm., vol. 286, pp. 99-102, 2014, doi: 10.1016/j.optcom.2012.08.055.

[40] M. Jeganathan, K. E. Wilson, and J. R. Lesh, "Preliminary analysis of fluctuations in the received uplink-beacon-power data obtained from the GOLD experiments," TDA Progress Report 42-124, Comm. Sys. and Research Sec., pp. 20-32, 1996.

[41] H. Henniger and O. Wilfert, “An introduction to free-space optical communications," J. Radioeng., vol. 19, no. 2, pp. 203-212, 2010.

[42] M. Toyoshima, T. Jono, T. Yamawaki, K. Nakagawa, and A. Yamamoto, "Assessment of eye hazard associated with an optical downlink in freespace laser communications," Proc. SPIE, Free Space Laser Comm. Tech. XIII, vol. 4272, 2001, doi: $10.1117 / 12.430783$.

[43] T. Dreischer et al., "Integrated RF-optical TT \& C for a deep space mission," Acta Astronautica, vol. 65, no. 11, pp. 1772-1782, 2009, doi: 10.1016/j.actaastro.2009.05.006.

[44] Z. Sodnik, H. Lutz, B. Furch, and R. Meyer, “Optical satellite communications in Europe,” Proc. SPIE, Free Space Laser Comm. Tech. XXII, vol. 7587, 2010, doi: 10.1117/12.847075

[45] S. Bloom, E. Korevaar, J. Schuster, and H. Willebrand, "Understanding the performance of free-space optics," J. Opt. Netw. (OSA), vol. 2, no. 6, pp. 178-200, 2003, doi: 10.1364/JON.2.000178.

\section{BIOGRAPHIES OF AUTHORS}
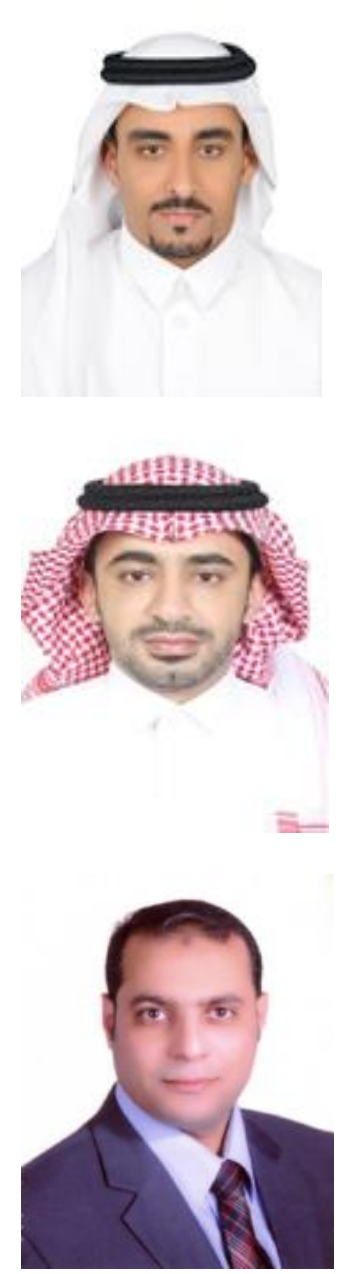

Dr. Alsharef Mohammad (D) Sd SC $\mathrm{P}$ He has been assigned as the head of Electrical Engineering Department at Taif University. His area of interest includes Wireless Communications, Digital Communications, Spread Spectrum Techniques and Continuous Phase Modulation Techniques. He can be contacted at email: M.alsharef@tu.edu.sa.

Dr. Mohammed S. Alzaidi (iD SC SC P He is currently an Assistant Professor with the Department of Electrical Engineering, Faculty of Engineering, Taif University, Saudi Arabia. $\mathrm{He}$ is also the Vice Dean of the Deanship of Scientific Research at Taif University. His research interests include nano molecular communications, wireless communications, signal processing, digital techniques, machine learning, and deep learning. He can be contacted at email: m.alzaidi@tu.edu.sa.

Dr. Mohamoud M. A. Eid (D) IS SC P Taif University, Electrical Engineering Department, Faculty of Engineering, He joins now the Taif University as an assistant professor in the Electrical Engineering Department, Faculty of Engineering. His interesting research focuses on optical sources, amplifiers, detectors, and sensors, optoelectronic devices. He can be contacted at email: m.elfateh@tu.edu.sa. 


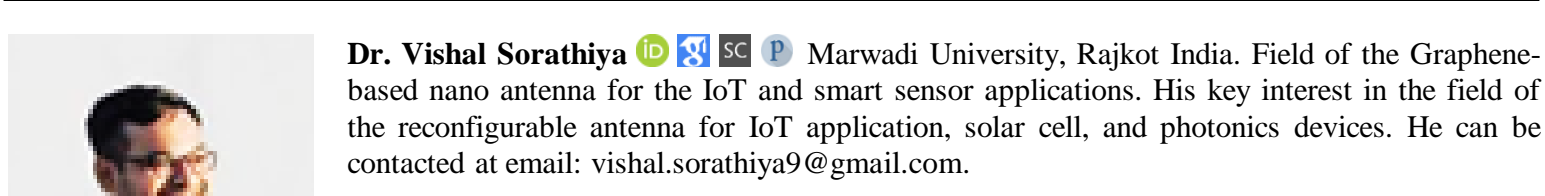

Dr. Vishal Sorathiya (iD 8) SC P Marwadi University, Rajkot India. Field of the Graphenethe reconfigurable antenna for IoT application, solar cell, and photonics devices. He can be contacted at email: vishal.sorathiya9@gmail.com.

Dr. Sunil Lavadiya (D) SC P Marwadi University. He currently works as an assistant professor in department of information and communication engineering, Marwadi University. He can be contacted at email: splavadiya@gmail.com.

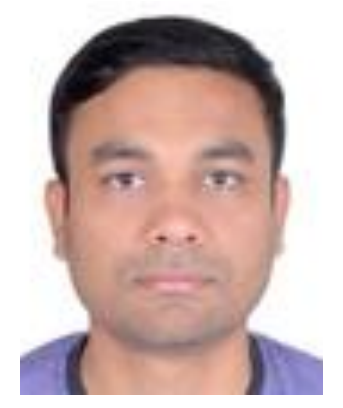

Dr. Shobhit K. Patel (D) 8d SC P Ph.D. on Electronics \& communication engineering at Charotar University of Science and Technology, Changa, India. He is currently working in the area of photonics, metamaterial, antenna, optics and artificial intelligence. He has been named in the list of "top $2 \%$ scientist worldwide identified by Stanford university" in 2021 . He can be contacted at email: shobhitkumar.patel@marwadieducation.edu.in.

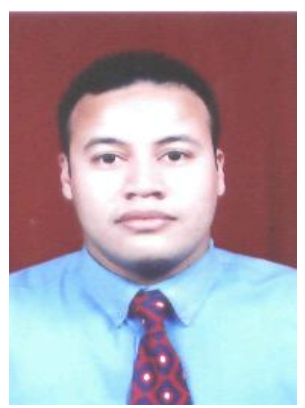

Prof. Ahmed Nabih Zaki Rashed (iD 8 SC P Faculty of Electronic Engineering, Menoufia University, Egypt. He has Published more than 325 Papers in high impacted Journals and Editor in Many international Journals. Prof. Rashed was selected among the top $2 \%$ of scientists published by Stanford University. He can be contacted at email: ahmed_733@yahoo.com. 